\title{
Smart Specialisation Concept Application in Universities: E-Business Online Studies Model Development
}

\author{
Aigars Andersons \\ Institute of Social, Economic and Hu- \\ manities Research, \\ Vidzeme University of Applied Sciences \\ Valmiera, Latvia \\ aigars.andersons@va.lv
}

\begin{abstract}
This paper discusses the Smart specialisation
\end{abstract} concept problems and challenges based on practice of Nordic and Baltic Higher Education Institutions. A particular focus of this research is devoted to the core understanding of the concept of Smart specialisation and its practical application for University level studies curriculum. EU Regional Cohesion Policy and other related EU policies play an important role to understand basic theoretical aspects for Smart specialisation. On the other hand, when specific case studies had been analysed in practice it is possible to see enormous variety of different misunderstandings of the matter. Even different study directions in the same University translate the Smart specialization terms mostly related to their individual study environments. As a result, it is possible to find in practice very different "Smart specialisation" concepts for technology, engineering, economics, IT and other study directions. As the research methodology/approach, the authors analyse the outcomes and challenges faced by different sets of case studies in Baltic and Nordic countries. Using EU, World Bank and other official national documents and publications, the authors explain the ways in which the Smart specialisation concept can be used in online learning environments. As an empirical research evidence there are analysed the outcomes from case studies - practical implementation of an online e-business study course jointly developed by 9 universities from Latvia, Finland, Iceland, Norway, Estonia, Lithuania, Sweden and Denmark supported by e-business field experts from Balkan area universities. Because of still existing gaps in Smart specialisation theoretical framework, the "grounded theory" approach have to be used more intensively when new and advanced theories have been created from practical outcomes of specific case studies. To solve a problem of Smart specialisation concept different translations and applications, authors of this paper propose to construct the teaching methodology of Smart specialisation concept into two consecutive levels - primary, as a core theory unique for all educators and secondary, as specific applied theories for each specific study direction.

Keywords-E-business, online studies, Smart specialization, teaching methodology.

\author{
Jozef Bushati \\ Faculty of Educational Sciences \\ University of Skodra, 'Luigj Gurakuqi", \\ Shkodra, Albania \\ jozefbushati@gmail.com
}

\section{INTRODUCTION}

This research paper analyses and provides few practical evidences valid for a European Parliament Preparatory Action centered on the refinement and implementation of the Research and Innovation Smart specialisation Strategy (RIS3).

Smart specialisation is an innovative approach that aims to boost growth and jobs in Europe, by enabling each region to identify and to develop its own competitive advantages. Through its partnership and bottom-up approach, Smart specialisation brings together local authorities, academia, business spheres and the civil society, working for the implementation of long-term growth strategies supported by European Union (EU) funds [1].

The process how to define and apply term "Smart specialisation" in Universities requires practical experimentation and empirical analysis that tests theoretical and learning aspects required these specialisations to be efficient and sustainable.

Guidelines from European Commission emphasizes that in "Smart specialisation" facilitation process the governments should have a central role [2], but how the government really performs these functions still remains uncertain, because it is a role that is adopted from various practical applications related with mentioned above concept nor coherent theories or mandatory regulations.

With an aim of the research and to test in practice different aspects of "Smart specialisation" concept for teaching and application purposes, nine Higher Education Institutions (HEI) from Baltic and Nordic areas Latvia joined their academic and scientific capacities to establish the collaborative network NOBANET (https://www. nordicbalticnet.info/).

List of involved HEIs:

1) Latvia - Vidzeme University of Applied Sciences, Valmiera,

2) Estonia - Estonian Entrepreneurship University of Applied Sciences, Tallinn and TTK University of Applied Sciences, Tallinn), 
3) Lithuania - Kauno Kolegija/ University of Applied Sciences, Kaunas,

4) Finland - Arcada University of Applied Sciences, Helsinki,

5) Iceland - Akureyri University/School of Business and Science, Akureyri,

6) Sweden - School of Education and Communication at Jönköping University,

7) Denmark - UCL University College Denmark, Odense,

8) Norway - Westerdals Oslo School of Arts, Communication and Technology.

In this paper had been examined outcomes from the partnership of mentioned above HEIs in creation of new type methodologies in a form of self-constructed online e-business study course with applied in practice "Smart specialisation" theories.

\section{Materials and Methods}

\section{A. Theoretical analysis of concept "Smart specialisation".}

"Smart specialisation" is actively discussed topic during the last decade by scientists and practitioners because of its special role into the regional development policy of European Union. One of the first published definitions states, "Smart specialisation is largely about the policy process to select and prioritize fields or areas where a cluster of activities should be developed" [3]. Evidently, the scope of this particular definition is too broad and unspecified for application in the same way for all specific business cases.

During the last years, this concept emerged into the more specified definition for Regional and Innovation Strategies for Smart specialisations (RIS3):

RIS3 is an integrated, place-based economic transformation agenda that does five important things:

a) It focuses policy support and investments on key national/regional priorities, challenges and needs for knowledge-based development, including ICT-related measures,

b) It builds on each country/region's strengths, competitive advantages and potential for excellence,

c) It supports technological as well as practicebased innovation aiming to stimulate private investment,

d) It gets stakeholders fully involved and encourages innovation and experimentation,

e) It is evidence-based and includes sound monitoring and evaluation systems [4].

The European Commission has developed a Smart specialisation platform where information about the RIS3 "Assessment wheel" is published. It is an assessment tool for RIS3 development in a country or [5].

For better understanding of "Smart specialisation" concept and further theory analysis framework there are two citations below from Foray et al. research paper. The first states that a key point is that Smart specialisation is not just for the "best" regions and technology leaders. On the contrary, this concept provides strategies and roles for any region. Indeed, the concept is built on the fact that there is not only one game in town in terms of R\&D and innovation; i.e. there are many other kinds of productive and potentially beneficial activities apart from the invention of fundamental knowledge needed for the development of general purpose technologies and tools [6]. The another one states that "Smart specialisation", on the other hand, involves the discovery of what makes a local knowledge base original and unique. Therefore, a commitment to "Smart specialisation" strategies can promote greater diversity of areas of knowledge and expertise within the system, thereby rendering the entire economy more able to enjoy the benefits of distinct local agglomeration economies and less vulnerable to both supply and demand shocks emanating in global markets [6].

After analysis of these two definitions, it is possible to draw a conclusion that nowadays "Smart specialisation" from HEIs academic prospective is less theoretical but mostly practical study subject dependent and morphing from one specific case and/or application to another.

\section{B. The Framework Development and Strategies of Smart specialisation.}

Authors of this research mainly agree with ideas proposed by Romanian scientist Steliana Sandu that Smart specialisation has already become a general strategy, with commitments from major decision-making individuals to instate them into policies and specific strategies. For the moment, practice is ahead of theory, meaning that in Europe and other countries strategies of smart growth or platforms of Smart specialisation elaborated from business and public governance practical activities. It is necessary to refine the theory and to choose the adequate database that would help to clarify some concepts and perfect the operationalization of this concept, to evaluate the possibilities of implementation and the means to monitor and coordinate it [7].

The Smart specialisation concept rests on two fundamental ideas:

1) Regions should focus on few areas where they have a significant impact (specialisation),

2) These domains of specialization should make use of existing strengths (smart) such as location, resources, or Science Technology and Innovation (STI) capabilities.

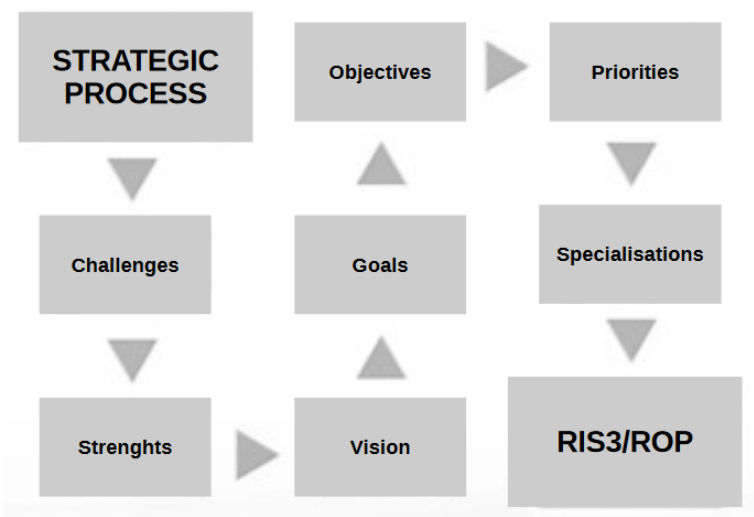

Fig. 1. Proposed key steps in the strategic process of selecting Smart specialisations [8], [9]. 
A significant difference between smart specialization and other policies is the active role of entrepreneurs in discovering new domains for innovation [10].

Clarification of Smart specialisation process is a key factor for further development of modern teaching methodologies for Universities. An existing situation how to select Smart specialisations for particular locations displayed in Fig. 1 (see above).

This specific roadmap scheme initially had been used also by NOBANET collaborative academic network joining nine Universities from Baltic and Nordic countries as a basic platform for research in Smart specialisation area described later in the next chapter of this paper.

The development of Smart specialisation strategies (RIS3) should promote the competitiveness of countries or regions. For national level, RIS3 helps concentrate resources and support innovations. Desk research identifies lack of regional level when comparing Smart specialisations in different countries [11].

The most frequently mentioned reason for gap of competences needed for Smart specialisation occurrence are inter-sectoral structural transformations. Failing branches do not have sufficient number of jobs available for employees with low qualifications. Jobs appear in emerging industries, but in this case, there are no qualified employees capable of meeting the requirements of jobs, most often related to modern technologies. The competence gap may be deepened by the maladjustment of curricula to the needs of the labor market [12].

An existing gap in understanding of Smart specialisation general framework among various theories and practical applications must be reduced and transformed into "smarter" structures. It is possible to realize collecting of real evidences of case studies and practical applications through use of "grounded theory" approach.

\section{Results AND Discussion}

\section{A. Evidence based approach for Smart} specialisation concept application.

The overall aim of NOBANET network is to create and widely disseminate new knowledge on successful internationalization of Nordic and Baltic SMEs. This aim achieved through close cooperation between HEIs and Small Medium Size Enterprises (SME) in all Nordic and Baltic countries with assistance of business entities and experts all over the world. Faculty, students and companies work closely together and across national borders, within educational courses and through real-life assignments in companies.

The five specific objectives of NOBANET network are:

1) Developing new learning materials on internationalization of SMEs,

2) Implementation real-life projects internationalization,

3) Developing partnership HEIs curricula to include internationalization of SMEs,

4) Creating models for sustainable cooperation between HEIs and SMEs,

5) Compilation of handbook: Internationalization of
Nordic and Baltic SMEs.

Previously developed (in Years 2014-2016) materials by NOBANET include:

1) Handbook on the Socio-Economic Environment of the Nordic and Baltic countries;

2) Handbook on the SMEs and Foreign Trade;

3) Handbook on the University - Business cooperation;

4) Best Practice examples on internationalization of SMEs;

5) Models for successful cooperation between HEIs and SMEs.

This research paper mainly covers two consecutive stages of NOBANET activities connected with Smart specialisation matters. The reasoning for actuality of particular research comes from NOBANET "Handbook on Internationalisation of Small and Medium-Sized Enterprises“, Part III, University - Business cooperation: model development and experience from practice [13]. The specific evidence-based case study covers Smart specialisation issues in ICT sector as detailed analysis of jointly developed e-business online study course within E-NOBANET network activity framework finished in Year 2018.

Smart specialisation studies have to contribute to the development of an evidence-based approach to Smart specialisation policies. It is a policy that builds on the prioritisation of resources, aiming at building knowledge and accelerating structural change [14]. Evidence-based policy (EBP) and practice means integrating experience, expertise, and judgement with the best available external evidence from systematic research [15].

Traditionally, different translations of the same subjects are not unique. Nowadays there are a number of digital tools available to bridge this gap and to create common understanding of Smart specialization matter. When time comes for a legacy relational database to migrate to semantic web or to be integrated with it, an important issue of determining similarity (compatibility) between two data models expressed in different ways arises [9].

However, bringing an evidence to bear on policy and practice raises at least two fundamental issues. The first concerns the type of evidence required to address policy needs, while the second refers to a set of challenges at the science-policy interface, in particular the question of how best to convey evidence to policy practitioners and practice [16]. The transition towards EBP has been related to the need for a sound basis for better regulation [17] and for better integration of scientific and academic theories and methodologies for the formulation, implementation, and evaluation purposes of Smart specializations.

\section{B. E-NOBANET case study.}

In lights of Smart specialisation teaching methodologies development process for students and SME`s specialists had been found that all Baltic and Nordic countries have some common areas of special concern. In the age of rapidly growing globalisation process, local SMEs are urgently lacking appropriate ICT competences. As an outcome from enabled problem, the NOBANET collaborative network had been established an innovative 
approach for Smart specialisation in ICT sector (interregional instead of traditional local or regional) by practical development of joint e-business course together with representatives of HEIs from all Nordic and Baltic countries and invited experts from Balkan area Universities. The goal of this activity stated as providing of students and SMEs business representatives with stateof-art competences and knowledge about basic principles of e-business and to improve practical skills how to use online tools and applications.

After the primary data analysis by joint researchers group it was decided to use an innovative Smart specialisation approach for this online study course with full e-business course (10 ECTS in total) divided in 10 individual topics, at amount of 1 ETCS each. Thus, students can take any number of topics they like to learn needed e-business competences in depth. This advanced approach improved existing methodologies with a possibility to avoid overlapping of mandatory studies of subjects already mastered elsewhere.

After the successful completion of the full study course, students will get an advanced knowledge and practical skills how to implement e-business applications in small and medium size enterprises and organizations, as well as the basic understanding how to create a simple/ average complexity web shop (shopping card) online.

TABLE 1

E-BUSINESS ONLINE STUDY COURSE CONTENT [18].

\begin{tabular}{|c|c|c|}
\hline $\begin{array}{c}\text { E-business online study course } \\
\text { topic }\end{array}$ & $\begin{array}{l}\text { Responsible } \\
\text { developer }\end{array}$ & $\begin{array}{l}\text { Enrolled } \\
\text { students }\end{array}$ \\
\hline $\begin{array}{l}\text { Introduction of e-business trends } \\
\text { and tools }\end{array}$ & Latvia & 116 \\
\hline $\begin{array}{l}\text { Marketing strategies and market } \\
\text { analysis }\end{array}$ & Iceland & 2 \\
\hline $\begin{array}{l}\text { Layout, usability and user expe- } \\
\text { rience }\end{array}$ & Sweden & 27 \\
\hline Content and SEO & Finland & 85 \\
\hline Online payment systems & $\begin{array}{l}\text { Latvia, Lith- } \\
\text { uania }\end{array}$ & 8 \\
\hline Delivery and distribution options & Estonia & 29 \\
\hline $\begin{array}{l}\text { Delivery terms, legal documents } \\
\text { and data security }\end{array}$ & $\begin{array}{l}\text { Es t o n i a, } \\
\text { Denmark }\end{array}$ & 23 \\
\hline Delivery analytics and KPI's & $\begin{array}{l}\text { Estonia, Fin- } \\
\text { land }\end{array}$ & 2 \\
\hline Test and evaluation & $\begin{array}{l}\text { F i n } 1 \text { a n d, } \\
\text { Norway }\end{array}$ & 3 \\
\hline Introduction into e-business course & Finland & 16 \\
\hline
\end{tabular}

E-learning course materials later were integrated in regular courses at NOBANET network partner universities and they are available (upon registration) on the Eliademy LMS platform [18]. The e-business study course is available as a self-paced, self-learning course with support and guidelines provided by the group of instructors. In addition, all developed e-learning materials are freely available for other similar projects and relevant topics.

\section{CONCLUSIONS}

The most of the interviews with entrepreneurs during the NOBANET collaborative academic network research activities enables that many SMEs owners and managers seem to have handled most things by themselves, through the individual creation of their own partnerships and relations. Just a few reported that they had gotten help from either governmental support or other kinds of business professional organizations like Business Finland, Finnvera, Finnish Health Technology Association, Business Sweden, Innovation Norway, Start-up Sauna Finland, Latvia Innovation and Development Agency and/or similar.

Until now, the vast majority of entrepreneurs, administrators and even university teachers understand concept of Smart specialisation in very different way in accordance with their individual experience and specific applications. Authors of this paper propose to divide Smart specialisation theory into two consecutive levels - a primary core theory unique for all and a secondary applied theories specific for each individual study direction.

From interviewed ICT sector representatives' prospective localised Smart specialisation principle is inadequate tool for rapidly changing global business markets. Nowadays businesses requires going beyond local or regional borders, without any limitations with full access and rights to participate in the global supply chains and sales networks.

Too much focus at regional level on few specific areas with a significant impact and intensive resources concentration only by exploiting of non-unique existing strengths such as geographical location, regional availability of natural and human resources or local ICT sector capabilities can significantly reduce global competitiveness for less developed regions where predominantly concentrated industries with low additional value.

Some University level business administration study programs need updates with core theoretical aspects of Smart specialisation concept with purpose to apply them into specific practical entrepreneurship models.

Smart specialization development process always have to be supplemented by various horizontal support measures, like collaborative networks, business advisory services, accessible and appropriate education systems and products sales promotion tools or platforms. Analysed in this research case study with free elective multi-topic e-business online study course created for students and SMEs specialists by NOBANET is good practice example here.

Introduction of Smart specialization concept in general is mostly valid for businesses built on use of local natural resources but less valid for businesses built on use of highly qualified human resources or sophisticated technologies. The last ones nowadays easily go beyond any local or regional boundaries and limits there are no need of "artificial" local or regional "Smart specialization".

Because of still existing gaps in Smart specialisation 
theoretical framework, the "grounded theory" approach have to be used more intensively when new and advanced theories have been created from practical outcomes of specific case studies.

\section{REFERENCES}

[1] European Commission, "Smart specialisation: Strengthening Innovation in Europe's Regions, Smart specialisation Platform, 2017, [Online]. Available: http://ec.europa.eu/regional policy/ sources/docgener/guides/smart_spec/strength_innov_regions en.pdf [Accessed February 11, 2019].

[2] European Comission, "Europe 2020 Flagship Initiative Innovation Union," Communication from the Commission to the European Parliament, the Council, the European Economic and Social Committee and the Committee of the Regions, Brussels, 2014, p. 20, [Online]. Available: http://ww.w.xploit-eu.com/pdfs/Europe $\% 202020 \% 20$ Flagship $\% 20$ Initiative $\% 20$ INNOVATION.pdf [Accessed February 24, 2019].

[3] D. Foray, P. A. David, and B. Hall, "Smart specialisation-the concept," Knowledge economists policy brief, 9(85), June 2009, p. 100 .

[4] European Commission, "Guide to Research and Innovation Strategies for Smart specialisations (RIS 3), Regional Policy, Brussels, 2012.

[5] S. Gemma and Z. Bulderberga, "Smart specialisation strategy assessment in Baltic States," In Research for Rural Development International Scientific Conference Proceedings (Latvia), Latvia University of Agriculture, 2017. http://dx.doi.org/10.22616/ rrd.23.2017.060

[6] D. Foray, P. A. David, and B. Hall, "Smart specialisation from academic idea to political instrument, the surprising career of a concept and the difficulties involved in its implementation", (No. EPFL-WORKING-170252), EPFL, 2011.

[7] S. Sandu, "Smart specialization concept and the status of its implementation in Romania," Procedia Economics and Finance, 3, Januaru 1, 2012, pp. 236-242. http://dx.doi.org/10.1016/S2212$\underline{\text { 5671(12)00146-3 }}$

[8] M. Piatkowski, T. Szuba, and G. Wolszczak, "Review of national and regional research and innovation strategies for smart specialization (RIS3) in Poland," World Bank Group, Washington: DC, 2014.

[9] I. Zarembo, A. Teilans, K. Barghorn, Y. Merkuryev, and G. Berina, "Methodology for Similarity Assessment of Relational Data Models and Semantic Ontologies," In 2016 International Confer- ence on Systems Informatics, Modelling and Simulation (SIMS), IEEE, June 1, 2016, pp. 119-123. http://dx.doi.org/10.1109/ SIMS.2016.21

[10] S. M. Krammer, "Science, technology, and innovation for economic competitiveness: The role of smart specialization in less-developed countries," Technological Forecasting and Social Change, 123, October 01, 2017, pp. 95-107. http://dx.doi.org/10.1016/j. techfore.2017.06.028

[11] M. Pelse and M Lescevica, "Smart Specialization Assessment in Latvia," In Economic Science for Rural Development Conference Proceedings, 42, April 15, 2016.

[12] R. Oczkowska, S. Wiśniewska, and P. Lula, "Analysis of the Competence Gap among Vocational School Graduates in the Area of Smart Specialization in Poland," International Journal for Quality Research, 11(4), December 1, 2017.

[13] Nobanet, "Handbook on Internationalisation of Small and Medium-Sized Enterprises. Part III, University - Business cooperation: model development and experience from practice," Nobanet Portal, 2016, [Online]. Available: https://docs.wixstatic.com/ugd/3ecad9 effb2129b4b54131ae0aeada1bae82e3.pdf [Accessed February 09, 2019].

[14] P. Kotnik and T Petrin, "Implementing a smart specialisation strategy: an evidence-based approach," International Review of Administrative Sciences, 83(1), March 2017, pp. 85-105. http:// dx.doi.org/10.1177/0020852315574994

[15] S. Nutley, H. Davies, and I. Walter, "Evidence-based policy and practice: cross-sector lessons from the United Kingdom," Social Policy Journal of New Zealand, 20, June 1, 2003, pp. 29-49.

[16] M. Dosso, B.R. Martin, and P. Moncada-Paternò-Castello, "Towards evidence-based industrial research and innovation policy," Science and Public Policy, 45(2), April 1, 2018, pp. 143-150. http://dx.doi.org/10.1093/scipol/scx073

[17] European Commission, "Better regulation for better results-An EU agenda", Communication from the Commission to the European Parliament, the Council, the European Economic and Social Committee and the Committee of the Regions, Strasbourg, May 19, 2015, [Online]. Available: http://ec.europa.eu/smart-regulation/better regulation/documents/com_2015 215 en.pdf [Accessed February 12, 2019].

[18] Nobanet, "E-business Study Course," Eliademy LMS system, 2019, [Online]. Available: https://eliademy.com/app/a/org/2522 [Accessed February 19, 2019]. 